\title{
Evaluation of Functional Outcomes after Stapes Surgery in Patients with Clinical Otosclerosis in a Teaching Institution
}

\author{
José Celso Rodriques de Souza ${ }^{1}$ Ricardo Ferreira Bento ${ }^{1}$ Larissa Vilela Pereira ${ }^{1,2}$ Liliane Ikari ${ }^{1}$ \\ Stephanie Rugeri Souza ${ }^{3}$ Ana Adelina Giantomasi Della Torre ${ }^{1}$ Anna Carolina de Oliveira Fonseca ${ }^{1}$

\footnotetext{
${ }^{1}$ Department of Otolaryngology, Universidade de São Paulo, School of Medicine, São Paulo, São Paulo, Brazil

2 Department of Otolaryngology, Anchieta Hospital, Brasília, DF, Brazil

${ }^{3}$ Department of Otolaryngology, Universidade de Mogi das Cruzes,

Mogi das Cruzes, São Paulo, Brazil
}

\begin{abstract}
Address for correspondence José Celso Rodriques de Souza, PhD, de Campos, 225 - Cerqueira César, São Paulo, SP 05403-010, Brazil (e-mail: jcelsosouza@hotmail.com).
\end{abstract} \\ Department of Otorhinolaryngology, HCFMUSP, Rua Dr. Ovídio Pires
}

\begin{abstract}
Keywords

- hearing loss

- otosclerosis

- stapes surgery

- stapes mobilization

Introduction Otosclerosis is a primary disease of the temporal bone that leads to stapes ankylosis. Hearing loss is the main symptom. Treatment includes surgery, medical treatment, and sound amplification therapy alone or in combination.

Objective To evaluate the functional outcomes of patients with clinical diagnosis of otosclerosis undergoing primary stapes surgery in a teaching institution.

Method Retrospective descriptive study.

Results A total of 210 ears of 163 patients underwent stapes surgery. Of the 163 patients, $116(71.2 \%)$ underwent unilateral surgery and 47 (28.8\%) underwent bilateral surgery. Six of the 210 operated ears had obliterative otosclerosis. The average preoperative and postoperative air-bone gap was 32.06 and $4.39 \mathrm{~dB}$, respectively. The mean preoperative and postoperative bone conduction threshold was 23.17 and $19.82 \mathrm{~dB}$, respectively. A total of 184 (87.6\%) ears had a residual air-bone gap $<10 \mathrm{~dB}$, and 196 (93.3\%) had a residual air-bone gap $\leq 15 \mathrm{~dB}$. Two patients $(0.95 \%)$ had severe sensorineural hearing loss.

Conclusion Stapes surgery showed excellent functional hearing outcomes in this study. This surgery may be performed in educational institutions with the supervision of experienced surgeons.
\end{abstract}

\section{Introduction}

Otosclerosis, also known as otospongiosis, is a primary disease of the otic capsule that leads to stapes ankylosis. ${ }^{1}$ Hearing loss is the main symptom. Complaints of continuous tinnitus and eventual vertigo are also observed. ${ }^{1,2}$ Otosclerosis is considered an autosomal dominant disease.

Genetic investigations in large families with autosomal dominant otosclerosis identified seven loci (OTSC15, OTSC7, OTSC8), although none of the corresponding genes have been found. However, a recent study suggests the implication of the T cell receptor $\beta$ locus as the causative gene in the OTSC2 region. ${ }^{3,4}$

Several researchers have come forth with association studies which have revealed the implication of COL1A1, ${ }^{3}$ TGFB1, BMP2, BMP4, ACE, AGT, and RELN in the disease development of otosclerosis, although the associations with COL1A1, ACE, and AGT are controversial. ${ }^{5,6}$

Clinical otosclerosis is present in $0.5 \%$ to $1.0 \%$ of the population and shows bilateral symptoms in $70 \%$ to $85 \%$ of received

March 3, 2015

accepted

June 28, 2015

published online

November 4, 2015
DOI http://dx.doi.org/

10.1055/s-0035-1563540. ISSN 1809-9777.
Copyright $\odot 2016$ by Thieme Publicações License terms Ltda, Rio de Janeiro, Brazil 
cases. Otosclerosis is more commonly diagnosed in women (female:male ratio of 2:1) and most frequently affects white individuals aged 20 to 40 years; it is less common in Asians and rare in Africans. ${ }^{1,2,8,9}$ Recently, according to Ueda et al, there has been an increasing incidence of otosclerosis in Japan, with a proportionate increase in indications for surgical treatment. ${ }^{9}$

Conductive or mixed hearing loss in patients with otosclerosis is determined by involvement of the stapes footplate. However, sensorineural hearing loss eventually occurs, and its cause has not yet been determined. As proposed by Candela et $\mathrm{al}^{10}$ the sensorineural component is due to invasion of the spiral ligament by the otosclerosis. In 1919, Wittmaack suggested that sensorineural hearing loss occurs as a consequence of toxic or inflammatory material deposited within the cochlea.

Treatment for otosclerosis includes surgery, medical treatment, and sound amplification therapy, alone or in combination. Otolaryngologists should analyze each patient individually and decide which treatment will provide the best functional outcomes.

Stapes mobilization to treat otosclerosis was initiated in 1952 by Rosen and modified in 1956 by John Shea, who performed the first stapedectomy. ${ }^{1,7-13}$ Stapes surgery is currently the treatment of choice for conductive hearing loss in patients with otosclerosis. Over time, there have been changes in surgical techniques, types of prostheses, and surgical materials, in an attempt to decrease the risks and complications of surgery and achieve better functional results. ${ }^{14,15}$ Furthermore, recently, the use of the laser technique is increasing gradually with developing technology. Palva, in 1978, reported good results with argon laser. ${ }^{16}$ From then on, all different types of laser systems, such as KTP, argon, erbium, YAG and $\mathrm{CO} 2$ lasers, were assessed for their suitability for stapes footplate perforation. ${ }^{17}$ However, none of them were believed to have any overwhelming advantage over the others in audiological results, post-operatively. ${ }^{18}$

Additionally, $\sim 10 \%$ of the patients with otosclerosis develop sensorineural hearing loss. Patients with long-term otosclerosis accompanied by severe mixed hearing loss can eventually develop far-advanced otosclerosis (FAO) ${ }^{19}$ FAO was first defined by House and Sheehy as an air conduction threshold of more than $85 \mathrm{~dB}$ and an immeasurable bone conduction threshold. ${ }^{20}$ Cochlear implantation (CI) has proven to be a good treatment option for patients with FAO. ${ }^{21}$ However, some authors report disappointing results because otospongiosis may hamper the electrode insertion and $\mathrm{CI}$ performance. ${ }^{19}$

Some authors have suggested that stapedotomy is best indicated for patients with otosclerosis because of its lower risk of sensorineural hearing loss and displacement of the prosthesis, while stapedectomy improves the lower frequencies of hearing. ${ }^{22}$

The goal of surgery is to improve communication, increase hearing level to acceptable thresholds, and enhancing sound amplification. The initial hearing improvement persists for many years. Many patients have severe mixed hearing loss or even deafness secondary to otosclerosis. Surgery can be performed in patients with a conductive component and good speech discrimination.

\section{Methods}

The authors of this study retrospectively reviewed data from 210 ears (163 patients) that underwent operations in the past 5 years by third-year residents under the supervision of the same otology surgeon. All patients with clinical otosclerosis had chosen estapedotomy/estapedectomy as a treatment to improve their hearing loss.

Pure tone audiometry was performed in all patients preoperatively and postoperatively in all frequencies. The bone conduction (BC) and air conduction (AC) were evaluated at the frequencies of $0.5,1.0,2.0$, and $3.0 \mathrm{KHz}$, and the preoperative and postoperative residual air-bone gap and its gain were calculated.

The initial surgery for all patients was stapedotomy; however, 32 patients had a floating footplate or fracture and, thus, underwent conversion to stapedectomy.

\section{Surgery}

All patients underwent operations using the same technique. The surgery was performed under general anesthesia, and the team used a transcanal approach with an auricular speculum and holder. First, a tympanomeatal flap was elevated. The chorda tympani nerve was preserved, and the bone wall was curetted to expose the oval window. The oval window was inspected to verify the focus of otosclerosis, and the ossicular chain was gently tested to confirm stapes fixation. The tendon of the stapes muscle was cut with Bellucci scissors. The stapes superstructure was disarticulated from the incus and fractured on the promontory. The distance between the footplate and the long process of the incus was measured, and the piston was cut with the addition of $0.25 \mathrm{~mm}$ to the measured distance. A third-year resident opened the stapes footplate in the central-posterior portion with a manual punch and the assistant surgeon delicately expanded it with a punch until it was slightly larger than $0.6 \mathrm{~mm}(0.7-0.8 \mathrm{~mm})$.

A teflon piston $0.6 \mathrm{~mm}$ in diameter and 4.25 to $4.50 \mathrm{~mm}$ in length was used in all cases. The oval window was naturally sealed with blood clot. The piston was expected to close spontaneously; when this did not occur, it was gently closed with McGee tweezers. The third-year resident placed all prostheses. These maneuvers were performed in the absence of any type of bleeding, especially after perforation of the stapes footplate. Postoperative corticosteroids and cinnarizine were routinely prescribed for 7 and 30 days, respectively.

The patients were hospitalized for two days and returned for follow-ups at 7, 15, and 30 days, postoperatively. Audiometric tests were performed at 45 to 60 days, 6 months, and 1 year, postoperatively.

\section{Results}

A total of 210 ears of 163 patients underwent stapes surgery. Of the 163 patients, 116 (71.2\%) underwent unilateral surgery and 47 (28.8\%) underwent bilateral surgery; 101 (48.1\%) 
Table 1 Patient characteristics

\begin{tabular}{|l|l|}
\hline Gender & $105(64.4)$ \\
\hline Female & $58(35.6)$ \\
\hline Male & \multicolumn{2}{|l|}{} \\
\hline Age in years & $43.56(10.81)$ \\
\hline Average (SD) & $43(16: 75)$ \\
\hline Median (min:max) & $116(71.2)$ \\
\hline Affected side & $47(28.8)$ \\
\hline Unilateral & $163(100.0)$ \\
\hline Bilateral & \multicolumn{2}{|l}{} \\
\hline Total & $101(48.1)$ \\
\hline Affected side & $109(51.9)$ \\
\hline Right & \\
\hline Left & $204(97.1)$ \\
\hline Obliterative otosclerosis & $6(2.9)$ \\
\hline No & $210(100.0)$ \\
\hline Yes
\end{tabular}

Abbreviation: SD, Standard deviation.

Data are presented as $n(\%)$, unless otherwise indicated.

underwent surgery on the right side, and 109 (51.9\%) underwent surgery on the left side. The majority of patients were female (64.4\%), and the mean age of all patients was $43.56 \pm 10.81$ years ( $\mathbf{-}$ Table $\mathbf{1}$ ).

The average preoperative and postoperative thresholds at the frequencies of 500,1000, 2000, and $3000 \mathrm{~Hz}$ and the average air-bone gap and related gains are presented in -Tables 2 and $\mathbf{3}$.

- Table 2 shows that the average preoperative and postoperative AC was 55.23 and $24.22 \mathrm{~dB}$, respectively. The mean preoperative and postoperative $B C 23.17$ and $19.82 \mathrm{~dB}$, respectively. The average preoperative and postoperative airbone gap was 32.06 and $4.39 \mathrm{~dB}$, respectively. There was statistically significant variation between the preoperative and postoperative times $(p<0.001)$ in the AC and BC thresholds and air-bone gap. Results show that $91.4 \%$ of patients showed improvement in the AC, $64.3 \%$ of patients showed improvement in the $\mathrm{BC}$, and $87.6 \%$ of patients had a successful surgical outcome, as determined by a postoperative air-bone gap of $<10 \mathrm{~dB} .{ }^{11}$ Seventeen (8.1\%) ears had a residual gap from 11 to $20 \mathrm{~dB}$, and 9 (4.3\%) had a residual gap of $>21 \mathrm{~dB}$.

Of the 17 patients with a residual air-bone gap from 11 to $20 \mathrm{~dB}$, four patients had a gap of $11.25 \mathrm{~dB}$, one patient had a gap of $12.00 \mathrm{~dB}$, five had a gap of $12.50 \mathrm{~dB}$, two had a gap of $13.75 \mathrm{~dB}$, three had a gap of $15.00 \mathrm{~dB}$, and two had a gap of $18.75 \mathrm{~dB}$. A total of 196 (93.3\%) patients had a residual gap of $\leq 15 \mathrm{~dB}$. Considering that the average preoperative gap was $32.06 \mathrm{~dB}$, a residual gap of $\leq 15 \mathrm{~dB}$ is an important audiometric gain.

Two patients $(0.95 \%)$ had severe sensorineural hearing loss. In the first, otorrhea associated with severe vertigo developed in the immediate postoperative period, and the patient was diagnosed with infectious labyrinthitis. The second patient presented with sudden deafness after a hypertensive crisis at three months, postoperatively.

- Table 3 shows that variations in the AC and BC were statistically lower in patients with obliterative otosclerosis ( $p=0.04$ and 0.009 , respectively) than in patients without obliterative otosclerosis, but the change in the air-bone gap was statistically similar between the two groups $(p=0.447)$.

\section{Discussion}

In 2006, Vincent et $\mathrm{al}^{22}$ performed a prospective study in which the results of 3050 stapedotomies were analyzed over a period of 14 years. The mean preoperative and postoperative air-bone gap was 25.6 and $1.7 \mathrm{~dB}$, respectively, and the gap was $\leq 10 \mathrm{~dB}$ in $94.2 \%$ of cases. In 2013, Oeken ${ }^{23}$ published a study of 256 cases of stapedotomy in which the postoperative air-bone gap was $\leq 10 \mathrm{~dB}$ in 220 cases (86\%). In 2013, Ataide et $\mathrm{al}^{24}$ observed the same result in $75.8 \%$ of patients undergoing stapedotomy. Therefore, the audiometric results obtained in the present study are consistent with those in the literature.

The mean preoperative and postoperative $\mathrm{BC}$ was 23.17 and $19.82 \mathrm{~dB}$, respectively. Thus, this improvement characterizes the phenomenon described by Carhart. ${ }^{7}$ The phenomenon is defined as a mechanical process involving the utilization of the energy of the sound wave that enters the external auditory canal and middle ear. This energy is not

Table 2 Preoperative and postoperative air and bone thresholds and air-bone gap

\begin{tabular}{|c|c|c|c|c|c|c|c|c|}
\hline & & Average & SD & Median & Minimum & Maximum & $n$ & $\mathrm{p}$ \\
\hline \multirow[t]{2}{*}{$A C$} & Pre & 55.23 & 12.04 & 52.5 & 24.0 & 108.0 & 210 & \multirow[t]{2}{*}{$<0.001$} \\
\hline & Post & 24.22 & 14.82 & 20.0 & 5.0 & 113.8 & 210 & \\
\hline \multirow[t]{2}{*}{$B C$} & Pre & 23.17 & 10.06 & 21.9 & 3.8 & 66.3 & 210 & \multirow[t]{2}{*}{$<0.001$} \\
\hline & Post & 19.82 & 11.10 & 17.0 & 5.0 & 71.3 & 210 & \\
\hline \multirow[t]{2}{*}{ Gap } & Pre & 32.06 & 8.26 & 31.3 & 11.3 & 58.8 & 210 & \multirow[t]{2}{*}{$<0.001$} \\
\hline & Post & 4.39 & 6.46 & 2.5 & 0.0 & 43.0 & 210 & \\
\hline
\end{tabular}

Abbreviations: AC, air conduction; BC, bone conduction; Gap, air-bone gap; SD, Standard deviation. 
Table 3 Thresholds according to the presence of obliterative otosclerosis and results of comparative tests

\begin{tabular}{|l|l|l|l|l|l|l|l|l|}
\hline & Obliterative Otosclerosis & Average & SD & Median & Minimum & Maximum & $\mathbf{n}$ & $\mathbf{p}$ \\
\hline \multirow{2}{*}{ Average AC gain } & No & 31.45 & 13.42 & 32.5 & -36.3 & 61.3 & 204 & $\mathbf{0 . 0 4 0}$ \\
\cline { 2 - 8 } & Yes & 16.04 & 18.83 & 13.8 & -5.0 & 42.5 & 6 & \\
\hline \multirow{2}{*}{ Average BC gain } & No & 3.59 & 9.18 & 3.8 & -36.0 & 29.0 & 204 & $\mathbf{0 . 0 0 9}$ \\
\cline { 2 - 9 } & Yes & -4.79 & 6.44 & -2.5 & -15.0 & 3.0 & 6 & \\
\hline \multirow{2}{*}{ GAP gain } & No & 27.93 & 9.69 & 27.6 & 0.0 & 52.5 & 204 & $\mathbf{0}$ \\
\cline { 2 - 9 } & Yes & 22.74 & 16.83 & 24.4 & -3.8 & 45.0 & 6 \\
\hline
\end{tabular}

Abbreviations: AC, air conduction; BC, bone conduction; Gap, air-bone gap; SD, Standard deviation.

used when fixation of the stapes footplate is present, as in patients with otosclerosis. ${ }^{7}$

Although Fischs reverse technique is safer for residents to perform because it avoids dislocation/subluxation of the incus, floating footplate, and even footplate fracture, the surgical field is limited. Moreover, it is contraindicated in patients with obliterative otosclerosis, a small or underexposed oval window by a prominent facial nerve. ${ }^{12}$

Therefore, appropriate surgical instruments are essential to obtain good stapedotomy/stapedectomy outcomes. Based on the present results, we currently avoid excessive manipulation of the stapes footplate and recommend stopping the surgery after a few attempts to perforate the footplate.

Two patients $(0.95 \%)$ presented with severe sensorineural hearing loss. The first patient developed sudden deafness three months, postoperatively. The second patient had an infectious labyrinthitis in the immediate postoperative period and audiometry on postoperative day 10 showed deafness in the operated ear.

\section{Conclusion}

Stapes surgery shows excellent functional hearing outcomes and can be performed in educational institutions under the supervision of experienced surgeons.

\section{References}

1 Glasscock ME III, Storper IS, Haynes DS, Bohrer PS. Twenty-five years of experience with stapedectomy. Laryngoscope 1995;105; (9 Pt 1):899-904

2 Rondini-Gilli E, Bozorg Grayeli A, Boutin P, et al. [Otosclerosis surgical techniques and results in 150 patients]. Ann Otolaryngol Chir Cervicofac 2002;119(4):227-233

3 HadjKacem H, Dhouib L, Mosrati MA, et al. Association of COL1A1 and TGFB1 polymorphisms with otosclerosis in a Tunisian population. Ann Hum Genet 2011;75(5):598-604

4 Thys M, Van Den Bogaert K, Iliadou V, et al. A seventh locus for otosclerosis, OTSC7, maps to chromosome 6q13-16.1. Eur J Hum Genet 2007b;15(3):362-368

5 Ealy M, Meyer NC, Corchado JC, et al. Rare variants in BMP2 and BMP4 found in otosclerosis patients reduce Smad signaling. Otol Neurotol 2014;35(3):395-400

6 Sommen M, Van Camp G, Liktor B, et al. Genetic association analysis in a clinically and histologically confirmed otosclerosis population confirms association with the TGFB1 gene but suggests an association of the RELN gene with a clinically indistinguishable otosclerosis-like phenotype. Otol Neurotol 2014;35(6):1058-1064

7 Moscillo L, Imperiali M, Carra P, Catapano F, Motta G. Bone conduction variation poststapedotomy. Am J Otolaryngol 2006; 27(5):330-333

8 Coker NJ, Duncan NO III, Wright GL, Jenkins HA, Alford BR. Stapedectomy trends for the resident. Ann Otol Rhinol Laryngol 1988;97(2 Pt 1):109-113

9 Ueda H, Miyazawa T, Asahi K, Yanagita N. Factors affecting hearing results after stapes surgery. J Laryngol Otol 1999;113(5):417-421

10 Häusler R. General history of stapedectomy. Adv Otorhinolaryngol 2007;65:1-5

11 Antoli-Candela F Jr, McGill T, Peron D. Histopathological observations on the cochlear changes in otosclerosis. Ann Otol Rhinol Laryngol 1977;86(6 Pt 1):813-820

12 Fisch U. Stapedotomy versus stapedectomy. Am J Otol 1982;4(2): 112-117

13 Mair IW. Occasional stapes surgery: a Norwegian experience. J Laryngol Otol 1989;103(3):259-262

14 Shabana YK, Allam H, Pedersen CB. Laser stapedotomy. J Laryngol Otol 1999;113(5):413-416

15 Zuur CL, de Bruijn AJ, Lindeboom R, Tange RA. Retrospective analysis of early postoperative hearing results obtained after stapedotomy with implantation of a new titanium stapes prosthesis. Otol Neurotol 2003;24(6):863-867

16 Palva T. Argon laser in otosclerosis surgery. Acta Otolaryngol 1987; 104(1-2):153-157

17 Fang L, Lin H, Zhang TY, Tan J. Laser versus non-laser stapedotomy in otosclerosis: a systematic review and meta-analysis. Auris Nasus Larynx 2014;41(4):337-342

18 Wegner I, Kamalski DMA, Tange RA, et al. Laser versus conventional fenestration in stapedotomy for otosclerosis: a systematic review. Laryngoscope 2014;124(7):1687-1693

19 van Loon MC, Merkus P, Smit CF, Smits C, Witte BI, Hensen EF. Stapedotomy in cochlear implant candidates with far advanced otosclerosis: a systematic review of the literature and metaanalysis. Otol Neurotol 2014;35(10):1707-1714

20 House HP, Sheehy JL. Stapes surgery: selection of the patient. Ann Otol Rhinol Laryngol 1961;70:1062-1068

21 Rama-López J, Cervera-Paz FJ, Manrique M. Cochlear implantation of patients with far-advanced otosclerosis. Otol Neurotol 2006; 27(2):153-158

22 Vincent R, Sperling NM, Oates J, Jindal M. Surgical findings and long-term hearing results in 3,050 stapedotomies for primary otosclerosis: a prospective study with the otology-neurotology database. Otol Neurotol 2006;27(8, Suppl 2):S25-S47

23 Oeken J. [Results of stapedotomies performed under general anesthesia]. HNO 2013;61(6):504-509

24 Ataide AL, Bichinho GL, Patruni TM. Audiometric evaluation after stapedotomy with Fisch titanium prosthesis. Braz J Otorhinolaryngol 2013;79(3):325-335 